\title{
Tempo, idade e cultura: uma contribuição à psicopatologia da depressão no idoso. Parte I: Temporalidade e cultura
}

\author{
Claudio Lyra Bastos
}

Procuramos aqui relacionar dois aspectos fundamentais das intuições culturais sobre a passagem do tempo - a temporalidade cíclica e a contínua - com a terapêutica médica e especialmente com a psicopatologia, numa visão crítica do constructo moderno da depressão no idoso. Inspirado em perspectivas de natureza antropológica, o texto se apóia na experiência clínica cotidiana e na atitude fenomenológica que orienta essa prática. Nas concepções culturais que tendem a perceber a passagem do tempo de forma predominantemente cíclica, o envelhecer é parte de um movimento eterno, e a família se perpetua em seus descendentes, nas suas tradições, no vínculo com a terra ou no exercício do ofício familiar. As transformações culturais que têm proporcionado a passagem para enfoques mais direcionais do tempo vão destacando cada vez mais o papel individual na história social. Quando mais difícil for a passagem de Weltanschauungen tradicionais, de tendência circular, fatalista, repetitiva e eterna, para outras de tendência individualizante, burocratizante, planejadora e sucessiva, maiores as dificuldades para uma senectude satisfatória e maior a tendência à medicalização desse fracasso.

Palavras-chave: Psicopatologia e cultura, temporalidade e medicina, depressão no idoso, psicogeriatria 


\section{Introdução}

Les jours sont peut-être égaux pour une horloge, mais pas pour un homme.

Marcel Proust

Pretendemos investigar as diferentes concepções de temporalidade e as suas relações com a práxis médico-psiquiátrica, especialmente na construção do conceito atual de depressão no idoso. Apesar de utilizar diversos referenciais teóricos de origem antropológica, o estudo se baseia na vivência da clínica psiquiátrica diária e em pressupostos fenomenológicos que a norteiam. A justificativa da pesquisa se estrutura na premente necessidade de se conhecer melhor, clinicamente, o paciente a quem a saúde pública se propõe atender, uma vez que qualquer proposta terapêutica eficaz precisa saber qual a sua demanda. Tanto o envelhecimento relativo da população - que proporcionou o surgimento da geriatria e da gerontologia - como o conceito abrangente de “depressão" como prioridade na saúde pública são problemas relativamente novos, cuja complexidade exige não apenas abordagens multidisciplinares, mas também transdisciplinares, como esta a que nos propomos.

A psicopatologia fenomenológica não busca fixar conjuntos de sintomas, mas sim o estabelecimento de relações de sentido; para isto a noção de temporalidade é fundamental, como mostrou Minkowski (1995). A antropologia apresenta a perspectiva de vivências culturais diversas para a passagem do tempo, conceito vital nesta pesquisa.

Os conceitos culturais de temporalidade, assim como também os de internalidade e externalidade, entre outras oposições dialéticas, fornecem interessantes elementos de compreensão para a atividade clínica em diversos referenciais sociais, inclusive aqueles ambientes de transição, plenos de ambigüidades, aos quais as perspectivas determinísticas sempre revelam absolutamente infensas. Tais conceitos permitem uma compreensão muito mais profunda do adoecer, e exigem uma abordagem fenomenológica da subjetividade, o que implica um retorno à clínica para se alcançar o social. 
$\begin{array}{lllllll}R & E & V & I & S & T & A\end{array}$

LATINOAMERICANA

DE PSICOPATOLOGIA

F U N D A M E N TA L

ano VIII, n. 4, dez/2005

Este trabalho se fundamenta no fato de que toda e qualquer cultura está vinculada a alguma idéia sobre a passagem do tempo, e essencialmente à idéia da transitoriedade do homem (Fraser, 1990; Rossi, 1992; Toynbee, 1994). A forma pela qual cada uma atua sobre a insanidade, o envelhecimento e a morte mostrase diferente, porém estando ligada à visão de mundo peculiar ao seu universo social. O propósito básico desta pesquisa, portanto, refere-se ao sentido e à forma dessa diferença, mais especificamente no que se refere, e à sua relação com o conceito médico de depressão na nosologia moderna.

Temos assim um problema básico, que é o processo de exclusão social do idoso, originado por duas instâncias:

a. Um processo de envelhecimento populacional que reverte expectativas e cria novas necessidades sociais, médicas e econômicas, para as quais a sociedade não se encontra preparada.

b. Uma inversão no papel cultural do idoso, que deixa de ser repositório da experiência e do saber da sociedade para se ver excluído da produção e manutenção de conhecimentos, tido como desinformado, ultrapassado, preso ao passado. Essa população idosa crescente não encontra mais respaldo nas tradições culturais e na família para viver satisfatoriamente a fase final da existência, com as suas angústias e sofrimentos, muitos deles inexoráveis.

Procuramos estudar a questão considerando de forma crítica dois dos seus aspectos essenciais:

a. A situação de exclusão, em muitos casos, tende a produzir ansiedade, estresse e um progressivo esvaziamento afetivo. Para dar conta do número cada vez maior de indivíduos nesta situação, a cultura científica moderna constrói um novo conceito de depressão que, fugindo dos princípios psicopatológicos fenomenológicos e psicodinâmicos anteriores, se propõe como rigorosamente "biológico" e procura atender às necessidades de classificação e controle da sociedade moderna sobre o estado mental da população. Nele transparece um movimento que procura biologizar e medicalizar todas as dificuldades existenciais, tirando da algibeira "soluções" psicofarmacológicas para todos os problemas possíveis da vida humana.

b. O momento atual é o de uma sociedade complexa e ambivalente, que se desenvolve sob um forte processo de aculturação e procura conviver simultaneamente com sistemas culturais aparentemente incompatíveis, inclusive com dois conceitos diferentes de passagem do tempo: um circular, eterno, que sempre retorna, que tende ao fatalismo e à paciência; o outro contínuo, limitado, progressivo, agitado e inconformista, onde o tempo corre.

Assim, procuramos compreender como essa população idosa que procura o hospital geral e "vai parar” no ambulatório de psiquiatria (seja por vontade 
própria, seja por encaminhamento a partir de outras especialidades), rotulada de “deprimida”, percebe a passagem do tempo em suas vidas, procurando saber como compreende a natureza do tratamento médico, quais as suas expectativas, seus vínculos religiosos etc. Propomos também que se investigue se entre as pessoas que tendem a apresentar quadros depressivos há predominância das que tenham sofrido ou venham sofrendo os processos mais bruscos de ruptura com o seu mundo cultural e com as suas concepções de finitude e de eternidade (Olshanski, 2001).

\section{A questão geral da temporalidade}

A idéia de tempo envolve uma multiplicidade de conceitos: tempo físico, biológico, subjetivo, cultural etc. Por esta razão, temos inúmeras dificuldades na definição da temporalidade que, em última análise, são causadas pela própria polissemia da palavra tempo.

Na filosofia ocidental, as idéias sobre a temporalidade motivaram muitos pensadores importantes, desde os comentários sobre a inefabilidade do tempo de Sto. Agostinho à postulação de condição a priori do pensamento por Kant, chegando ao fundamento ontológico em Heidegger. A física moderna estimulou fortemente esse debate ao trazer novas questões, antes quase impensáveis (Prigogine, 1992; Ruelle, 1994; Szamosi, 1994; Barreau, 1996).

\section{O tempo físico e a relatividade}

À cosmologia de Newton, que concebia tempo e espaço em termos absolutos, já se contrapunha o seu contemporâneo Leibnitz. No entanto, só no século XX a idéia de tempo e espaço relativos se impôs. A relatividade provocou uma revolução no pensamento humano, não apenas na física teórica. O tempo passou a ser visto como algo inseparável do espaço, como uma quarta dimensão deste, e a simultaneidade como um evento apenas local, noções intuitivamente inconcebíveis. De acordo com Einstein (1994), quando nenhum sistema de coordenadas (sistema inercial) é usado como base de referência, não há sentido em afirmar que eventos que se produzem em diferentes pontos no espaço ocorrem simultaneamente. É em conseqüência disto que o espaço e o tempo são fundidos num contínuo uniforme quadrimensional.

O espaço e o tempo físicos eram vistos pela física newtoniana como entidades absolutas, independentes uma da outra, onde a força de gravitação nada tinha a ver com a geometria. Já o espaço-tempo einsteiniano formava um todo 


\section{$\begin{array}{lllllll}R & E & V & I & S & T & A\end{array}$ \\ LATINOAMERICANA \\ DE PSICOPATOLOGIA \\ F U N D A M E N TA L \\ ano VIII, n. 4, dez/2005}

único, cuja "curvatura” correspondia à gravidade. No entanto, a relatividade e a mecânica quântica não modificaram a possibilidade de reversibilidade do tempo em relação à mecânica de Newton (Gell-Mann, 1996). A segunda lei da termodinâmica, que postula a entropia ou desorganização progressiva e inevitável de sistemas fechados, é a que se baseia num sentido único para o tempo. Notese que o crescimento da complexidade biológica - tanto no sentido filogenético como ontogenético - não traz qualquer incompatibilidade com a idéia de entropia por serem os seres vivos sistemas abertos, em permanente troca, e não fechados, como aqueles a que se refere a segunda lei da termodinâmica.

Na física dos sistemas macroscópicos, a teoria do caos e da complexidade permite explicar a historicidade (irreversibilidade) dos eventos. Já nos níveis subatômicos, os físicos experimentais estão até hoje procurando demonstrar a irreversibilidade do tempo ("flecha do tempo") (Novello, 1995; Nunes, 1996; Klein e Spiro, 1996). Toda a nossa idéia de intencionalidade e historicidade depende de um tempo irreversivelmente direcionado (Hawking, 1988; Atlan, 1992; Davies, 1998; Coveney, 1998).

De acordo com Pomian (1993), São Tomás de Aquino sustentou a idéia de que as criaturas corpóreas existem no tempus (tempo cíclico, de nascimento, corrupção e morte), ao passo que as criaturas espirituais existem no ævum (tempo direcional, sujeito a mudanças), e apenas Deus existe na ceternitas (eternidade, tempo imutável). Bem antes, Santo Agostinho havia proposto que o tempo havia sido criado por Deus juntamente com o Universo, de forma que qualquer questão sobre o que haveria antes da Criação não teria nenhum sentido. Curiosamente, essa concepção em muito se assemelha à dos físicos atuais, que entendem que o tempo surgiu com o Big Bang.

A ciência não pode assim ter por objeto a eternidade - ou o determinismo absoluto -, mas apenas os fenômenos temporais que constituem a nossa realidade, que não se confunde com os nossos modelos explicativos. Os cientistas hoje se confrontam com diversas flechas direcionais do tempo, em busca de uma teoria que as unifique, sem nem mesmo ter certeza de que essa procura por uma causa essencial, seja mesmo uma questão científica (Piettre, 1996). Aproximando-se de Santo Agostinho, o físico teórico Anthony Zee (1992) confessa: “... eu realmente não compreendia, como ainda não compreendo, a natureza do tempo. E ninguém também compreende.”

\section{O tempo biológico}

Sabemos que todos os organismos vivos dispõem de diversos osciladores biológicos ("relógios vivos") que se influenciam mutuamente e que sofrem a in- 
fluência externa dos sincronizadores (Zeitgebers), como os ciclos diários e sazonais de luz e temperatura que estão sempre "acertando" os relógios internos. Nos mamíferos, os principais marca-passos são os núcleos supraquiasmáticos do hipotálamo, que recebem informações sobre o fotoperíodo - diretamente da retina através de fibras específicas dos nervos ópticos - e também a glândula pineal ou epífise, que secreta o hormônio melatonina. Também os ritmos mais longos, como por exemplo os ciclos reprodutivos, sofrem a influência sazonal de forma semelhante. São dois os principais relógios que nos controlam: um regula o ciclo sono-vigília e o outro regula a temperatura corporal e os ritmos metabólicos. Estes ritmos fisiológicos intrínsecos são chamados ritmos circadianos porque sua duração se aproxima das 24 horas (situam-se entre 22 e 28 horas, sendo chamados ultradianos quando são menores que o dia e infradianos quando o ultrapassam). Precisam, portanto, ser regulados permanentemente.

Alguns desses ritmos parecem estar de alguma forma relacionados à regulação do humor. Os ciclos sazonais de luminosidade, muito marcantes nas latitudes altas, parecem influir no humor, assim como os níveis hormonais - como os da tireóide e os corticosteróides - que seguem oscilações circadianas (Poirel, 1982; Cipolla-Neto et al. 1988; Reinberg, 1997).

Modelos matemáticos dos ritmos fisiológicos vêm sendo estudados. Neles, os mecanismos dos sistemas dinâmicos altamente complexos (ou caóticos) dos osciladores biológicos podem ser entendidos como tendentes a constantes bifurcações que separam a via patológica da via fisiológica ou normal (Glass \& Mackey, 1988).

\section{O tempo psicológico}

No desenvolvimento da mente infantil, a absoluta inconsciência do tempo um eterno presente - evolui para uma progressiva ampliação da consciência do passado e da expectativa do futuro. Segundo Piaget (1970), mesmo quando nas suas primeiras fases a criança age dentro de uma seqüência temporal, a consciência dessa temporalidade só vem com o desenvolvimento. Desta forma, no início ela pode ordenar sua atividade no tempo sem se dar conta disto, ou seja, sem nenhuma representação seqüencial dos eventos ou qualquer serialidade temporal.

Na consciência temporal da criança se vai revelando cada vez mais importante a idéia de futuro, pois a sua identidade individual e o seu reconhecimento social se encontram como que armazenados lá, naquele adulto que ela será quando crescer. Durante a adolescência o processo de construção da 
$\begin{array}{lllllll}R & E & V & I & S & T & A\end{array}$

LATINOAMERICANA

DE PSICOPATOLOGIA

F U N D A M E N TA L

ano VIII, n. 4, dez/2005

identidade absorve todas as energias emocionais no momento presente, enquanto que o passado infantil é deixado de lado e o futuro paira incerto num horizonte distante, paradoxalmente muito mais longínquo do que durante a infância. Finalmente, a senectude tende a se dedicar ao passado, já que o presente é pouco gratificante e o futuro não existe. Assim, cabe à idade adulta produzir o equilíbrio entre passado, presente e futuro em que se constitui a maturidade.

Santo Agostinho, no livro XI de suas célebres “Confissões”, inquire-se sobre a natureza do tempo, observando que o presente está sempre deixando de existir, enquanto que o passado não é mais e o futuro é apenas uma potencialidade (Sto. Agostinho, 1952). Segundo ele existem em nossa mente três tempos: o presente do passado, que é a memória; o presente do presente, que é a atenção, e o presente do futuro, que é a expectativa. Memória, atenção, pensamento e afetividade envolvem aspectos importantes do exame clínico psicopatológico.

A afetividade representa um papel fundamental na formação dos registros mnêmicos, que formam a base da noção de temporalidade. A neurofisiologia nos mostra que as estruturas do sistema límbico-hipocampal estão diretamente ligadas à afetividade e à mnemogênese. Na mente adulta, a memória anterógrada, afetivamente ligada à curiosidade, ao gosto pelo novo, forma uma consciência de tempo progressivo, em permanente expectativa de mudança. A memória retrógrada forma a consciência de um tempo caracterizado por fenômenos que se repetem, cuja previsibilidade cria a experiência.

A memória produz o registro do tempo interno. Podemos propor um tempo afetivo, ao observarmos a diminuição aparente do fluxo do tempo interno nos estados de prazer, e a sua aceleração no sofrimento. Constatamos ainda um tempo cognitivo na medida em que a intensa aquisição de informações acelera o sentido do tempo interno na infância, e a redução do ritmo cognitivo diminui o fluxo temporal interno na velhice. Em certas lesões cerebrais pode ocorrer uma perda da aquisição de novas informações, ocasionando um presente permanente, fixo numa época passada. Nas lesões hipocampais, ocorre uma diminuição da capacidade de consolidação dos registros mnêmicos prévios, ocasionando um esquecimento rápido. Nas lesões diencefálicas, como na síndrome de Korsakoff, diminui o próprio registro ou sua codificação; assim o esquecimento permanece normal, mas o processo de registro torna-se muito lento. Ocorre aí uma perda da localização dos registros no tempo (isolamento contextual), sem que haja perda da percepção do fluxo do tempo.

A percepção do tempo encontra-se alterada sob a ação de drogas estimulantes, nos estados reativos de alarme, nos estados febris, no delirium, nas lesões dos gânglios basais, da substância negra e do estriado. Sob a influência desses estados, a passagem do tempo pode parecer lentificada (quando o sujeito se sente acelerado e o mundo tornado vagaroso) ou então mais rápida (quando o sujeito 
se percebe lentificado e, o mundo, acelerado). Um usuário de cocaína e um doente parkinsoniano tendem a apresentar percepções opostas da passagem do tempo, ocasionadas pelas diferenças na atividade dopaminérgica dos gânglios da base.

Na psicopatologia, sabemos que alguns distúrbios afetivos têm uma certa relação com os ritmos fisiológicos, com a sazonalidade e com o fotoperíodo. Jaspers (1973) discrimina as alterações da consciência do curso temporal (aceleração ou lentificação do tempo, perda da consciência do tempo, desrealização do tempo, imobilização do tempo), da consciência da extensão temporal, da consciência do presente em relação ao passado e ao futuro, da consciência do futuro e ainda as alterações esquizofrênicas da consciência do tempo (desagregação, confusão).

Podemos considerar que nos estados neuróticos o presente (vida atual) se vê sobrepujado pelo passado (reminiscências) ou pelo futuro (a antecipação e a ansiedade) (Sutter, 1983). Nos quadros esquizofrênicos parece interromper-se a passagem do tempo, não havendo mais vida nem prazer. Na depressão melancólica como que desaparece o futuro, tomado pelo fatalismo (tudo já está escrito, já é passado), pela desesperança e pela idéia de fim e de morte. De acordo com Binswanger (1987), o futuro se mostra como que invadido pelo passado. Nos estados maníacos parece não haver mais vínculos entre o passado e o futuro, dando lugar à inconseqüência e à ausência de limites.

Minkowski (1995) destaca a redução da estrutura temporal na mania e na depressão, utilizando a diferenciação feita por Hönigswald e por Straus entre o tempo imanente (Ich-Zeit: tempo do eu) e o tempo transitivo (Welt-Zeit: tempo do mundo). Observa que na depressão melancólica, o tempo imanente se retarda em relação ao tempo transitivo e a inibição se instala.

Alonso-Fernandez (1968) procura sistematizar a temporalidade psicopatológica de acordo com a predominância do futuro (neuroses de angústia), do presente (histéricos, maníacos, alcoólicos, dementes, oligofrênicos), ou do passado (depressivos). Relaciona também a temporalidade à expectativa, à esperança e à capacidade de suportar a frustração.

Mais recentemente, Fuchs (2001) propôs uma interpretação da melancolia como resultado de uma dessincronização da relação temporal entre organismo e ambiente, ou indivíduo e sociedade.

\section{O tempo subjetivo}

Achamos conveniente distinguir o tempo subjetivo do tempo psicológico, porque esta última expressão pressupõe um propósito explicativo ou interpretativo implícito, uma intenção de aplicabilidade clínica ou científica, que não existe 


\section{$\begin{array}{lllllll}R & E & V & I & S & T & A\end{array}$

necessariamente na primeira. Na psicopatologia, vista de acordo com Minkowski (1995, 1999) como psicologia do patológico (e não como patologia do psicológico) a temporalidade constitui a essência das vivências e das relações de sentido entre elas. Com relação ao tempo subjetivo, diz Portella Nunes (1976):

... quando se intenta descrever o puro momento presente, resulta que sempre e necessariamente aparecem elementos constitutivos que o transcendem no passado e no futuro. O homem projeta, espera, teme, e em tudo que faz, atualmente, preexiste um elemento de futuro. As situações em que sempre nos encontramos impõem-nos urgências e dificuldades que orientam nossa relação com o futuro... (p. 42)

Estas observações se juntam às palavras de Marcel Proust em À la recherche du temps perdu (À l’ombre de jeunes filles en fleurs): "Nous appelons notre avenir l’ombre de lui-même que notre passé projette devant nous.”

Voltamos assim à observação de Santo Agostinho, de que o presente está sempre deixando de existir, enquanto que o passado não é mais e o futuro é apenas uma potencialidade. De acordo com Merleau-Ponty (1996): “... passado não é passado, nem o futuro é futuro. Eles só existem quando uma subjetividade vem romper a plenitude do ser em si, desenhar ali uma perspectiva, ali introduzir o não-ser” (p. 564). Assim, acrescenta, “Um passado e um porvir brotam quando eu me estendo em direção a eles”. Citando Paul Claudel, Merleau-Ponty afirma que o tempo não é uma sucessão de agoras, nem “... uma linha, mas uma rede de potencialidades” (p. 556).

Indo além da introspecção, a fenomenologia de Husserl (1994) procura “esclarecer o a priori do tempo explorando a consciência do tempo.” De acordo com Husserl, a imanência do tempo torna unificada a multiplicidade das vivências. Já o pensamento existencialista de Heidegger (1995) vai além na busca de uma visão ontológica da temporalidade, a qual é constitutiva do próprio Dasein. Assim, das inter-relações entre o mundo e o sujeito transparece um conceito de ser-nomundo que permite abarcar essa multiplicidade de conceitos objetivos e subjetivos da temporalidade. Para a consciência humana, o tempo é o horizonte necessário na sua apreensão do ser.

Como que confirmando os filósofos, a ciência alterou muitas das idéias intuitivas ingênuas que tínhamos sobre o tempo e a simultaneidade dos eventos. Segundo Bertrand Russell (1994): “O tempo não é uma ordem cósmica única. O fato de o tempo ser próprio de cada corpo (...) envolve mudanças nas noções de substância e causa, e sugere a substituição de uma substância que atravessa diferentes estados por uma série de eventos."

A ação, o pensamento e o sentimento humanos só existem dentro do fluxo do tempo. A autoconsciência do homem e a constatação da passagem do tempo 
lhe permitem tomar conhecimento da inexorabilidade da morte. Em sua Crítica da razão pura, Kant (1969) fez ver que o tempo e o espaço não são referenciais universais, mas concepções a priori da mente humana:

O tempo ... é a forma real da intuição interna. Conseqüentemente, o tempo não é real como objeto. Mas, se eu mesmo ou um outro ente me pudesse perceber sem esta condição da sensibilidade, estas mesmas determinações que nós nos representamos atualmente como mudanças nos dariam um conhecimento em que não se encontrará mais a representação do tempo, nem, por conseguinte, a de mudança, não existiriam. Sua realidade empírica permanece, pois, como condição de todas as nossas experiências. Mas a realidade absoluta não se pode, segundo vimos, conceder ao tempo.

A fenomenologia de Husserl e Heidegger mostra que a subjetividade é inseparável do pensamento humano, e que a objetividade livre, neutra e externa é inexeqüível. Da mesma forma, não há conhecimento atemporal, ou fora do campo temporalizante da consciência (Nowotny, 1992). Buscar um referencial absoluto é uma fantasia e uma perigosa armadilha. Voltando às palavras de Zee (1992): “O tempo é o único conceito da física sobre o qual não podemos falar sem que apareça, em algum nível, a consciência.”

A ciência moderna tem confirmado que a nossa capacidade de entender o mundo tem seus limites: assim, os problemas da física astronômica e da mecânica quântica podem ser trabalhados no nível matemático, mas nos escapam à compreensão. As verdades da física newtoniana - que pensávamos absolutas - restringem-se apenas à nossa fração de universo. A vida - no sentido biológico - nos fornece referenciais internos: os relógios biológicos, e o mundo físico nos dão referenciais temporais externos: os movimentos dos corpos celestes e as suas conseqüências, os dias e as estações do ano, que regulam os nossos relógios biológicos. No entanto, é a nossa vivência psíquica que determina a idéia de temporalidade, de acordo com Henri Bergson (1970). Estava na intuição da duração o cerne de sua doutrina sobre o tempo, diferençiando-a do tempo abstrato.

A cultura, evidentemente, tem uma parte importante na formação desse substrato psíquico. No campo da literatura, Jorge Luís Borges explorou magnificamente as possibilidades do tempo subjetivo, em relação com o tempo biológico e o tempo físico, em pequenas obras-primas como Milagre secreto, $\mathrm{O}$ imortal, A escrita do Deus e O jardim dos caminhos que se bifurcam, narrativa sobre uma novela imaginária, da qual reproduzimos um trecho: “O jardim dos caminhos que se bifurcam é uma enorme charada, ou parábola, cujo tema é o tempo; (...) é uma imagem - uma imagem incompleta, mas não falsa, do universo tal como o concebia Ts’ui Pen. Diferentemente de Newton e de Schopenhauer, 
$\begin{array}{lllllll}R & E & V & I & S & T & A\end{array}$

LATINOAMERICANA

DE PSICOPATOLOGIA

F U N D A M E T A L

ano VIII, n. 4, dez/2005

seu antepassado não acreditava num tempo uniforme, absoluto. Acreditava em infinitas séries de tempos, numa rede crescente e vertiginosa de tempos divergentes, convergentes e paralelos. Essa trama de tempos que se aproximam, se bifurcam, se cortam ou que secularmente se ignoram, abrange todas as possibilidades. Não existimos na maioria desses tempos; nalguns existe o senhor e não eu. Noutros, eu, não o senhor; noutros, os dois. Neste, que um acaso favorável me surpreende, o senhor chegou a minha casa; noutro, o senhor, ao atravessar o jardim, encontrou-me morto; noutro, digo estas mesmas palavras, mas sou um erro, um fantasma”.

\section{O tempo cultural}

Mesmo que se entenda, como Kant, que o tempo e o espaço sejam intuições a priori da mente humana, deve-se levar em conta que esses conceitos nem sempre são unitários nem entendidos no mesmo nível de síntese (Elias, 1998). Em outras épocas e outras culturas vemos que o tempo e o espaço podem ser particularizados e fragmentados. Muitos relatos antropológicos mencionam concepções de tempo e espaço estritamente vinculadas ao momento e ao local. O conhecido relato bíblico do Livro de Josué, em que Deus faz o Sol parar no céu - para proporcionar a Israel a conquista de Canaã - demonstra essa perspectiva.

Como observou William James (1890, p. 622-3), para a nossa mente, o registro intuitivo do tempo não vai além de horas ou dias. Além desse limite, a concepção se torna absolutamente simbólica. São as datas e os eventos que nos criam a referência; a sua quantidade simboliza a extensão temporal. É o seu caráter social que nos permite construir uma noção do tempo. Coube ao registro simbólico cultural a tarefa de vincular o tempo natural (os ciclos da natureza) aos eventos humanos.

A partir da semana judaica (ver Zerubavel, 1985) e do horarium beneditino, a sociedade passou a criar seu próprio tempo, abstrato e independente da temporalidade marcada pela natureza. A cultura propicia um modelo arquetípico para as concepções do tempo, e as diversas dicotomias temporais podem ser encontradas entre as sociedades: tempo sagrado e tempo profano, monocronia e policronia, sincronia e assincronia etc.

Nas culturas tradicionais, onde predomina o tempo circular, fortemente ligado aos ciclos da natureza, e o espaço simbólico predomina sobre o espaço físico, observamos com mais freqüência uma certa tendência a temporalizar o espaço. 
Como exemplo, a frase: “Tal lugar dista a um dia e meio daqui”. Nessas mentalidades, o passado tende a ser uma referência muito mais importante do que o futuro, pois nos acontecimentos pretéritos encontram-se todas as respostas. Muitas vezes acredita-se numa antiga Idade de Ouro, que um dia retornará.

Nas sociedades modernas, onde a temporalidade predominante é seqüencial, estabelecida pelo homem, e o espaço objetivo predomina sobre o subjetivo (Szamosi, 1994; Wertheim, 1999), tende-se mais a espacializar o tempo, que é cartografado em mapas, que são os calendários, agendas, planners etc. Dizemos: “Tal evento fica próximo deste outro”, ou “Tal dia é distante daquele”. O futuro torna-se então a principal referência, já que o passado é visto com desprezo e todos esforços se direcionam ao porvir. Daí surge a noção de progresso como valor (ver Janet, 1928).

Aqui no Brasil, vemos surgir uma estranha perspectiva da seqüência do tempo, carregada de ambigüidade, aonde o futuro e o progresso são vistos como metas permanentes, ao mesmo tempo em que se mostram desconectadas do passado e do presente. Como a criança, que imagina um futuro fantasioso, o Brasil vive um permanente sonho do País do Futuro que não tem passado. A construção de Brasília, a capital “moderna” e desligada da tradição e da história do país, representa esse ideal de esquecer o passado e criar um novo mundo assentado sobre o nada.

Assim, em linhas gerais, as concepções culturais do tempo mais relevantes, ou pelo menos as que mais interessam ao contexto da terapêutica e da psicopatologia, ao nosso ver, são as de tempo cíclico e tempo contínuo, sobre as quais nos estenderemos posteriormente (com relação à ciência em geral, ver Gould, 1991; Hess, 1995).

Na página seguinte reproduzimos o gráfico esquemático de uma “carta do tempo” (Hall, 1996), que procura ilustrar de forma integrada as diversas dimensões dos conceitos de tempo.

\section{Referências}

Alonso-Fernandez, F. Fundamentos de la psiquiatria actual. Madrid: Paz Montalvo, 1968. $2 \mathrm{vv.}$

AtLan, H. Entre o cristal e a fumaça. Rio de Janeiro: Zahar, 1992.

Augustine, Saint. T. The Confessions of St. Augustine. New York: Pocket Books, 1952. Barreau, H. Le Temps. Paris: PUF, 1996. 
$\begin{array}{lllllll}R & E & V & I & S & T & A\end{array}$

LATINOAMERICANA

DE PSICOPATOLOGIA

F U N D A M E N TA L

ano VIII, n. 4, dez/2005

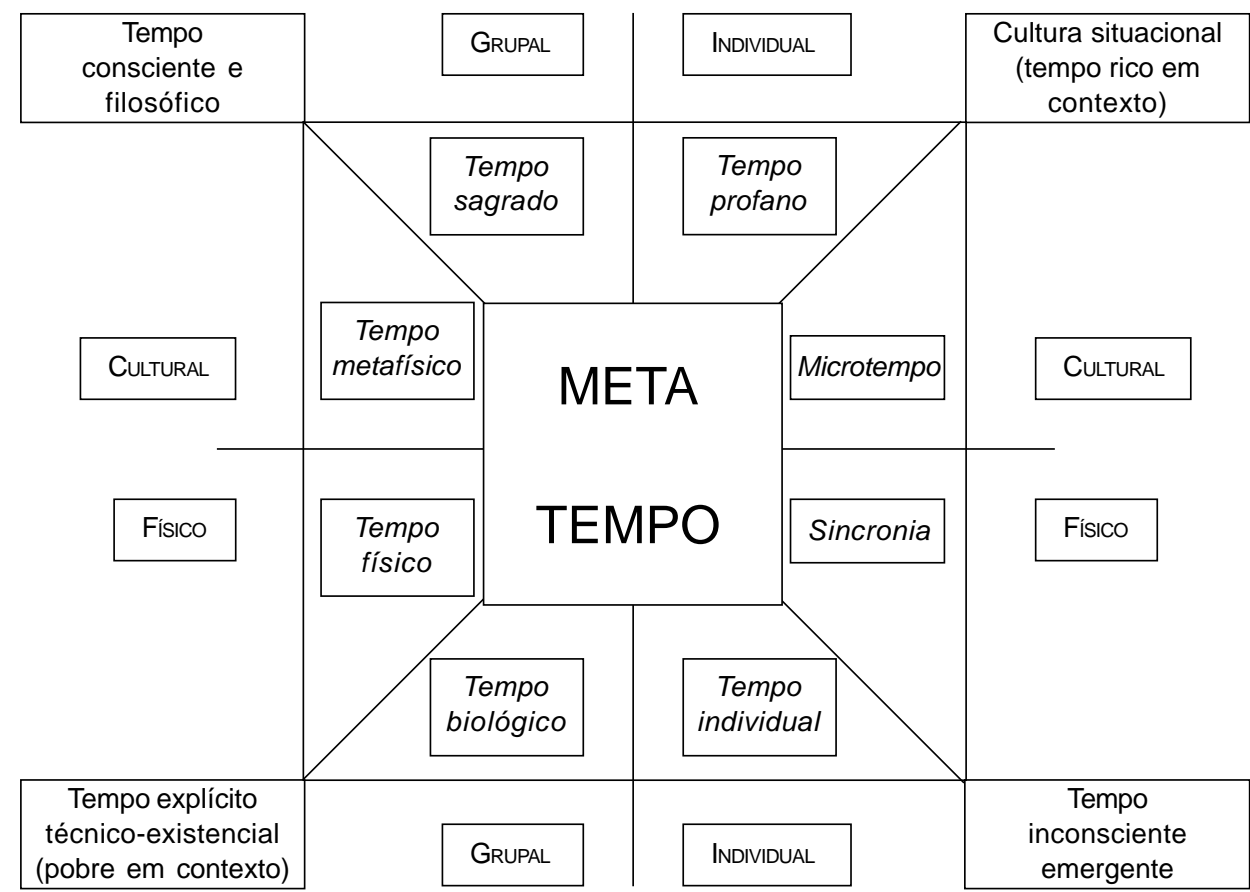

Bergson, E. (1888) Essai sur les Données Immédiates de la Conscience. 14. ed. Paris: PUF, 1970. $182 \mathrm{p}$.

Binswanger, L. Mélancolie et manie. Paris: PUF, 1987.

Cipolla Neto, J.; Marques, N. e Mena Barreto, L. S. Introdução ao estudo da cronobiologia. São Paulo: Ícone/Edusp, 1988.

Coveney, P. e Highfield, R. A flecha do tempo. São Paulo: Siciliano, 1993.

Davies, P. O enigma do tempo. Rio de Janeiro: Ediouro, 1998.

Einstein, A. Espaço-tempo. In: O tesouro da enciclopédia britânica. 2. ed. Rio de Janeiro: Nova Fronteira, 1994.

Elias, N. Sobre o tempo. Rio de Janeiro: Jorge Zahar, 1998.

Fraser, J. T. Of Time, Passion, and Knowledge. Princeton: Princeton Univ. Press, 1990.

Fuchs, T. Melancholia as a Desynchronization: Towards a Psychopathology of Interpersonal Time. Psychopathology, v. 34, n. 4, p. 179-86, 2001.

Gell-Mann, M. O Quark e o Jaguar. Rio de Janeiro: Rocco, 1996. 
Glass, L. e Mackey, M. C. From Clocks to Chaos: the Rhythms of Life. Princeton: Princeton University Press, 1988.

Gould, S. J. Seta do tempo, ciclo do tempo. São Paulo: Companhia das Letras, 1991.

Hall, E. A dança da vida. Lisboa: Relógio D’Água, 1996.

Hawking, S. Uma breve história do tempo. Rio de Janeiro: Rocco, 1988.

HeIDEgGer, M. Ser e tempo. Petrópolis: Vozes, 1995.

Hess, D. J. Science and Technology in a Multicultural World. New York: Columbia University Press, 1995.

HusSERL, E. Lições para uma fenomenologia da consciência interna do tempo. Lisboa: Imprensa Nacional/Casa da Moeda, 1994.

James, W. The Principles of Psychology. New York: Henry Holt, 1890. 2 vv.

JANET, P. L'évolution de la mémoire et de la notion du temps. Paris: Édition A. Chahine, 1928. Tome III: L’organisation du temps, p. 419-624.

JASPERS, K. Psicopatologia geral. Rio de Janeiro: Atheneu, 1973. 2 vv.

Kant, I. Crítica da razão pura. Rio de Janeiro: Tecnoprint, 1969.

KLEIn, É. e Spiro, M. Le Temps et sa flèche. Paris: Flammarion, 1996.

Merleau-Ponty, M. Fenomenologia da percepção. São Paulo: Martins Fontes, 1996.

Minkowski, E. Le temps vécu. Paris: PUF, 1995.

Traité de psychopathologie. Paris: Synthélabo, 1999. (Les Empêcheurs de Penser en Rond).

Novello, M. Os diferentes vazios e os diferentes tempos da cosmologia. In: Katz, C. (org.). Temporalidade e psicanálise. Petrópolis: Vozes, 1995.

Nowotny, H. Le Temps à Soi: Genèse et Structuration d'un Sentiment du Temps. Paris: MSH, 1992.

Nunes, B. Experiências do tempo. In: Novaes, A. (org.). Tempo e história. São Paulo: Companhia das Letras, 1996.

Olshansky, S. J. e Carnes, B. A. The Quest for Immortality: Science at the Frontiers of Aging. New York: W.W. Norton, 2001.

Piaget, J. A noção do tempo na criança. Rio de Janeiro: Record, 1970.

Piettre, B. La science et le temps. In: Meheut, M. (org.). Penser le temps. Paris: Ellipses, 1996.

Poirel, C. Los ritmos circadianos en psicopatologia. Madrid: Alhambra, 1982.

Pomian, K. Tempo/temporalidade - Enciclopédia Einaudi. Lisboa: Imprensa Nacional/ Casa da Moeda, 1993. v. 29.

Portella, E. Obsessão e delírio. Rio de Janeiro: Imago, 1976. 


\section{$\begin{array}{lllllll}R & E & V & I & S & T & A\end{array}$ \\ LATINOAMERICANA \\ DE PSICOPATOLOGIA \\ F U N D A M E N TA L \\ ano VIII, n. 4, dez/2005}

Prigogine, I. e Stengers, I. Entre o tempo e a eternidade. São Paulo: Companhia das Letras, 1992.

ReInBerg, A. Les rythmes biologiques. Paris: Flammarion, 1997.

Rossı, P. Os sinais do tempo. São Paulo: Companhia das Letras, 1992.

Ruelle, D. Acaso e caos. 2. ed. São Paulo: Unesp, 1994.

Russel, B. Conseqüências filosóficas da teoria da relatividade. In: O tesouro da enciclopédia britânica. 2. ed. Rio de Janeiro: Nova Fronteira, 1994.

SutTer. L'anticipation. Paris: PUF, 1983.

Szamosi, G. Tempo e espaço. Rio de Janeiro: Jorge Zahar, 1994.

Toynbee, A. O ciclo do tempo. In: O tesouro da enciclopédia britânica. 2. ed. Rio de Janeiro: Nova Fronteira, 1994.

Wertheim, M. The Pearly Gates of Cyberspace. New York: W.W. Norton, 1999.

Zee, A. Time Inversion. In: Shore, W. H. (ed.). Mysteries of Life and the Universe. New York: Harcourt, 1992.

Zerubavel, E. Hydden Rhythms: Schedules and Calendars in Social Life. Berkeley: University of California Press, 1981.

\section{Resumos}

Buscamos aquí relacionar dos aspectos fundamentales de las intuiciones culturales sobre el pasaje del tiempo - la temporalidad cíclica y la continua - con la terapéutica médica y más especialmente con la psicopatología, en una visión critica del constructo moderno de la depresión en la vejez. Inspirado en perspectivas antropológicas, el texto busca apoyo en la experiencia clínica diaria y en la actitud fenomenológica que la orienta. En las concepciones culturales del tiempo que tienden a percibir su pasaje de forma predominantemente cíclica, envejecer es parte de un movimiento eterno, y la familia se perpetúa en sus descendientes, en sus tradiciones, en el vínculo con la tierra o en el ejercicio del trabajo familiar. Las transformaciones culturales que han proporcionado el pasaje para enfoques más direccionales del tiempo van destacando cada vez más el rol individual en la historia social. Cuanto más dificultoso sea el pasaje de Weltanschauungen tradicionales, de tendencia circular, fatalista, repetitiva y eterna para otras de tendencia individualizante, burocratizante, planeadora y sucesiva, más grandes las dificultades para una senectud satisfactoria así como la tendencia a la medicalización de este fracaso.

Palabras claves: Psicopatología y cultura, temporalidad y medicina, depresión en el anciano, psicogeriatría 
Nous cherchons ici à mettre en rapport deux aspects fondamentaux des conceptions intuitives culturelles sur la passage du temps - la temporalité cyclique et la temporalité continue - avec la thérapeutique médicale et notament avec la psychopathologie, dans une vision critique du concept moderne de dépression chez la personne agée. Inspiré des perspectives de nature anthropologique, le texte se fonde sur l'expérience clinique quotidienne et sur l'attitude phénoménologique guidant cette pratique. Dans les conceptions culturelles qui tendent à percevoir le passage du temps comme cyclique, le vieillissement fait partie d'un mouvement éternel et la famille se perpétue par ses descendants, ses traditions, ses liens avec la terre ou par l'exercice du métier familial. Les transformations culturelles qui ont une approche plus directionnelle du passage du temps montrent de plus em plus le rôle individuel dans l'histoire social. Plus il sera dificile de passer des Weltanschauungen traditionnelles, tendant à la circularité, à la répétition, au fatalisme et à l'éternité, à d'autres Weltanschauungen de tendance à l'individualisation, à la bureaucratie, à la planification et à la succession, plus les difficultés d'avoir une vieillesse satisfaisante seront grandes et la tendance à la médicalisation de ce problème sera plus importante.

Mots clés: Psychopatologie et culture, temporalité et médicine, dépression de la personne âgée, psychogériatrie

Two fundamental aspects of cultural intuitive conceptions of time's passage cyclic and continuous temporality - are here related to medical therapy and psychopathology, in a critical view of depression in old age as a modern construct. Although inspired by anthropological perspectives this paper is based on daily clinical experience and on a phenomenological attitude. In predominantly cyclical cultural perceptions of time the process of ageing is part of an eternal movement, and families perpetuate themselves in their descendants, in their traditions, in land ties or in the practice of familiar crafts or skills. Cultural transformations that give rise to more directional approaches of time's passage tend to implement individual roles more and more in social history. The more difficult the change from fatalist, repetitive, eternal cycling traditional Weltanschauungen to individualizing, bureaucratizing, planning and successive ones, the larger the chances of an unsuccessful old age and "medicalization" of this failure.

Key words: Psychopathology and culture, temporality and medicine, depression and ageing, psychogeriatrics

Versão inicial recebida em julho de 2005

Aprovado para publicação em outubro de 2005 